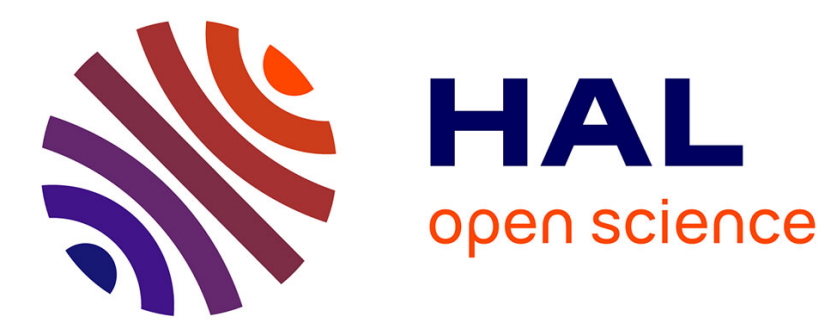

\title{
Proline-mediated Knoevenagel condensation in ethanol: a sustainable access to p-hydroxycinnamic acids
}

\author{
Cedric Peyrot, Aurélien Peru, Louis Mouterde, Florent Allais
}

\section{To cite this version:}

Cedric Peyrot, Aurélien Peru, Louis Mouterde, Florent Allais. Proline-mediated Knoevenagel condensation in ethanol: a sustainable access to p-hydroxycinnamic acids. ACS Sustainable Chemistry \& Engineering, 2019, 7 (10), pp.9422-9427. 10.1021/acssuschemeng.9b00624 . hal-02883331

\section{HAL Id: hal-02883331 \\ https://hal.science/hal-02883331}

Submitted on 29 Jun 2020

HAL is a multi-disciplinary open access archive for the deposit and dissemination of scientific research documents, whether they are published or not. The documents may come from teaching and research institutions in France or abroad, or from public or private research centers.
L'archive ouverte pluridisciplinaire HAL, est destinée au dépôt et à la diffusion de documents scientifiques de niveau recherche, publiés ou non, émanant des établissements d'enseignement et de recherche français ou étrangers, des laboratoires publics ou privés. 


\title{
Proline-mediated Knoevenagel condensation in ethanol: a sustainable access to $p$-hydroxycinnamic acids
}

\author{
Cédric PEYROT ${ }^{1}$, Aurélien PERU ${ }^{1}$, Louis MOUTERDE ${ }^{1}$, Florent ALLAIS $^{1 *}$ \\ ${ }^{1}$ Chaire Agro-Biotechnologies Industrielles, AgroParisTech, CEBB, 3 rue des Rouges Terres, 51110 Pomacle, France.
}

Knoevenagel, p-hydroxycinnamic acids, green chemistry, heterogeneous catalysis, L-proline, magnesium oxide, sinapic acid, ferulic acid, caffeic acid, coumaric acid

\begin{abstract}
Naturally occurring $p$-hydroxycinnamic acids were obtained using an amine- and toxic solvent-free Knoevenageltype pathway. This method uses not only non-toxic reagents (i.e., L-proline and magnesium oxide as catalyst) and ethanol as green solvent, all reagents and solvent being renewable and accessible at low price. By combinaing a Design of Experiment and a One Variobale At a Time optimization (OVAT), the different reaction parameters optimized in order to favor sinapic acid synthesis over that of the two other possible by-products, the corresponding di-acids and vinyl phenols. This alternative to classical Knoevenagel reaction allowed to substitute traditional pyridine- and piperidine-catalyzed pathway while obtaining each natural $p$ hydroxycinnamic acids in good conversions and yields (50-85\%).
\end{abstract}

\section{INTRODUCTION}

Knoevenagel reaction is one of the most studied reactions in the recent years ${ }^{1}$. It allows to access, among others, $p$ hydroxycinnamic acids that are key intermediates for the synthesis of a large range of (bio)active molecules: non endocrine disruptive bisphenol A susbtitutes ${ }^{2}$, antioxidants ${ }^{3}$, anti-UV ingredients ${ }^{4}$ or renewable polymers and resins or $^{5}$ However its use is limited by the reaction conditions that involve large amounts of pyridine as solvent and aniline or piperidine as catalyst ${ }^{6}$. Pyridine is toxic and may induce serious health damages. Although aniline and piperidine are less dangerous, reducing their utilization is desirable.

Few alternatives have been described in the literature. Among them, ionic liquids offer high solubility and recyclability $^{7}$, however industrial applications are compromised due to their high price ${ }^{8}$. Microwave-assisted Knoevenagel was also investigated, Mouterde et al. demonstrated that such activation reduces both solvent volume and reaction time, while providing the targets in excellent yields (85-92\%) and limiting the production of the corresponding vinylphenols through decarboxylation. ${ }^{9}$ Even if the methodology seems to be efficient in terms of yield, the industrial scale-up remains, unfortunately, limited by the microwave reactor size and the presence of piperidine. Another alternative consists in performing a solvent-free Knoevenagel reaction which permits to decrease the amount of catalyst needed and reduce the reaction time. ${ }^{10}$ Solvent-free reactions or bio-based solvents, conform with the principles of green chemistry, are ideal conditions researched by the industries. Different catalysts such as Lewis acids $\left(\mathrm{LiOH}, \mathrm{ZnCl}_{2}\right)$, heterogeneous solid bases or aminoacids have also been investigated. ${ }^{10-11}$ Combinations of these different approaches have been also investigated such as aminoacids catalyst in presence of ionic liquid or PEG ${ }^{12}$. More recently, De Winter et al performed an aldol condensation in presence of L-proline and magnesium oxide, nontoxic and naturally occurring compounds. This method allowed the synthesis of $\alpha, \beta$-unsaturated ketone in excellent yields ${ }^{13}$. In the present work, this approach has been implemented and optimized to synthesize natural $p$ hydroxycinnamic acids from the corresponding $p$-hydroxybenzaldehydes.

\section{EXPERIMENTAL SECTION}

General: Knoevenagel condensations were performed in round bottom flask topped by air cooling column. Evaporations were conducted under reduced pressure. ${ }^{1} \mathrm{H}$ NMR spectra of compounds in the indicated solvent were recorded at $300 \mathrm{MHz}$ at $20{ }^{\circ} \mathrm{C}\left[{ }^{1} \mathrm{H} \mathrm{NMR}\right.$ : $\left(\mathrm{CD}_{3}\right)_{2} \mathrm{CO}$ residual signal at $\delta=2.05 \mathrm{ppm}$; DMSO residual signal at $\delta=2.50 \mathrm{ppm}] .{ }^{13} \mathrm{C}$ NMR spectra in the indicated solvent were recorded at $75 \mathrm{MHz}$ at $20{ }^{\circ} \mathrm{C}\left[{ }^{13} \mathrm{C}\right.$ NMR: $\left(\mathrm{CD}_{3}\right)_{2} \mathrm{CO}$ residual .signal at $\delta=206.26$ and $29.84 \mathrm{ppm}$; DMSO residual signal at $\left.\delta=39.52 \mathrm{ppm}\right]$. The entire 
assigned NMR spectras are presented in the Supporting information. All reported yields are uncorrected and refer to purified products. All reagents were purchased from Sigma- Aldrich or TCI and used without purification.

Optimized method for synthesis of $p$-hydroxycinnamic acids: The corresponding $p$-hydroxybenzaldehydes $(1 \mathrm{~g}$, 1.0 equiv), malonic acid (2.0 equiv) and L-proline ( 0.5 equiv) were mixed in ethanol $(0.5 \mathrm{M})$. Stirring and thermal heating $\left(90{ }^{\circ} \mathrm{C}\right)$ were applied during 16 hours. The reaction mixture was then concentrated under vacuum. Conversion yields were determined by ${ }^{1} \mathrm{H}$ NMR spectrometry and crude products were extracted with a mixture AcOEt/HCl (1 M). Organic layers were washed with brine, dried over anhydrous $\mathrm{MgSO}_{4}$ and concentrated under vacuum. Crude mixture was then purified by column chromatography on silica gel using appropriate eluent system (cyclohexane:AcOEt 50-50 to 100\% AcOEt).

p-Coumaric acid. ${ }^{1} \mathrm{H}$ NMR $\left(300 \mathrm{MHz},\left(\mathrm{CD}_{3}\right)_{2} \mathrm{CO}\right): \delta=7.61(\mathrm{~d}, J=15.96 \mathrm{~Hz}, 1 \mathrm{H}, \mathrm{H}-3), 7.57(\mathrm{~s}, 1 \mathrm{H}, \mathrm{H}-5 \mathrm{or}$ H-9), 7.54 (s, 1H, H-5 or H-9), $6.91(\mathrm{~s}, 1 \mathrm{H}, \mathrm{H}-6$ or H-8), $6.88(\mathrm{~s}, 1 \mathrm{H}, \mathrm{H}-6$ or H-8), $6.34(\mathrm{~d}, J=15.93 \mathrm{~Hz}, 1 \mathrm{H}$, H-2). ${ }^{13} \mathrm{C}$ NMR $\left(75 \mathrm{MHz},\left(\mathrm{CD}_{3}\right)_{2} \mathrm{CO}\right): \delta=168.3$ (s, C-1), 160.5 (s, C-7), 145.6 (d, C-3), 130.9 (d, C-5 and C9), 127.0 (s, C-4), 116.7 (d, C-2), 115.7 (d, C-6 and C-8).

Caffeic acid. ${ }^{1} \mathrm{H}$ NMR $\left(300 \mathrm{MHz},\left(\mathrm{CD}_{3}\right)_{2} \mathrm{CO}\right): \delta=7.55(\mathrm{~d}, J=15.9 \mathrm{~Hz}, 1 \mathrm{H}, \mathrm{H}-3), 7.16(\mathrm{~d}, J=2.04 \mathrm{~Hz}, 1 \mathrm{H}$, $\mathrm{H}-9$ ), 7.04 (dd, $J=2.01$ and $8.22 \mathrm{~Hz}, 1 \mathrm{H}, \mathrm{H}-6), 6.86$ (d, $J=8.16 \mathrm{~Hz}, 1 \mathrm{H}, \mathrm{H}-5), 6.27$ (d, $J=15.9 \mathrm{~Hz}, 1 \mathrm{H}, \mathrm{H}-2)$. ${ }^{13} \mathrm{C}$ NMR $\left(75 \mathrm{MHz},\left(\mathrm{CD}_{3}\right)_{2} \mathrm{CO}\right): \delta=168.2(\mathrm{~s}, \mathrm{C}-1), 148.6(\mathrm{~s}, \mathrm{C}-7), 146.2(\mathrm{~s}, \mathrm{C}-8), 145.9(\mathrm{~d}, \mathrm{C}-3), 127.5$ (s, C4), 122.4 (d, C-5), 116.2 (d, C-6), 115.6 (d, C-2), 115.1 (d, C-9).

Ferulic acid. ${ }^{1} \mathrm{H}$ NMR $\left(300 \mathrm{MHz},\left(\mathrm{CD}_{3}\right)_{2} \mathrm{CO}\right): \delta=7.61(\mathrm{~d}, J=15.9 \mathrm{~Hz}, 1 \mathrm{H}, \mathrm{H}-3), 7.34(\mathrm{~d}, J=1.89 \mathrm{~Hz}, 1 \mathrm{H}$, $\mathrm{H}-9), 7.15(\mathrm{dd}, J=1.86$ and $8.22 \mathrm{~Hz}, 1 \mathrm{H}, \mathrm{H}-6), 6.87(\mathrm{~d}, J=8.16 \mathrm{~Hz}, 1 \mathrm{H}, \mathrm{H}-5), 6.39(\mathrm{~d}, J=15.93 \mathrm{~Hz}, 1 \mathrm{H}, \mathrm{H}-$ 2), 3.92 (s, 3H, H-11). ${ }^{13} \mathrm{C}$ NMR (75 MHz, $\left.\left(\mathrm{CD}_{3}\right)_{2} \mathrm{CO}\right): \delta=168.3$ (s, C-1), 149.9 (s, C-8), 148.6 (s, C-7), 145.9 (d, C-3), 127.4 (s, C-4), 123.8 (d, C-5), 116.0 (d, C-2), 115.8 (d, C-6), 111.2 (d, C-9), 56.2 (q, C-11).

Sinapic acid. ${ }^{1} \mathrm{H}$ NMR $\left(300 \mathrm{MHz},\left(\mathrm{CD}_{3}\right)_{2} \mathrm{CO}\right): \delta={ }^{1} \mathrm{H}$ NMR $\left(300 \mathrm{MHz},\left(\mathrm{CD}_{3}\right)_{2} \mathrm{CO}\right): \delta=7.59(\mathrm{~d}, J=15.87$ $\mathrm{Hz}, 1 \mathrm{H}, \mathrm{H}-3), 7.02$ (s, 2H, H-5 and H-9), 6.41 (d, $J=15.87 \mathrm{~Hz}, 1 \mathrm{H}, \mathrm{H}-2), 3.89$ (s, 6H, H-11 and H-12). ${ }^{13} \mathrm{C}$ NMR $\left(75 \mathrm{MHz},\left(\mathrm{CD}_{3}\right)_{2} \mathrm{CO}\right): \delta=168.3(\mathrm{~s}, \mathrm{C}-1), 148.9$ (s, C-8 and C-6), 146.3 (d, C-3), 139.3 (s, C-7), 126.1 (s, C-4), 116.1 (d, C-2), 106.7 (d, C-5 and C-9), 56.6 (q, C-11 and C-12).

\section{RESULTS AND DISCUSSION}

Knoevenagel reactions are known to be really sensitive to reaction conditions and it has been shown that each reaction parameter impacts significantly $p$-hydroxycinnamic acid production as well as that of side-products (di-acid and vinyl phenol) (Scheme 1). Indeed high temperature is an essential factor that promotes decarboxylation of $p$ hydroxycinnamic di-acids into $p$-hydroxycinnamic acids (Scheme 1$)^{14}$. Moreover, high temperatures also induce malonic acid degradation and acetic acid generation ${ }^{15}$. This degradation requires the use of several equivalents of malonic acid to ensure $p$-hydroxybenzaldehydes consumption. Furthermore, high temperatures can lead to a second decarboxylation that generates vinyl phenols ${ }^{16}$. Many mechanisms have been proposed. Based on the thermodynamic study performed by Bermudez et al using piperidine as activating group, the proposed mechanism shown in scheme 1 illustrates perfectly the positive effect of temperature on the first decarboxylation step, but also its negative impact leading to vinyl phenols formation and malonic acid degradation ${ }^{14}$. Finding the right temperature that will favor one product or the other is therefore quite challenging. 

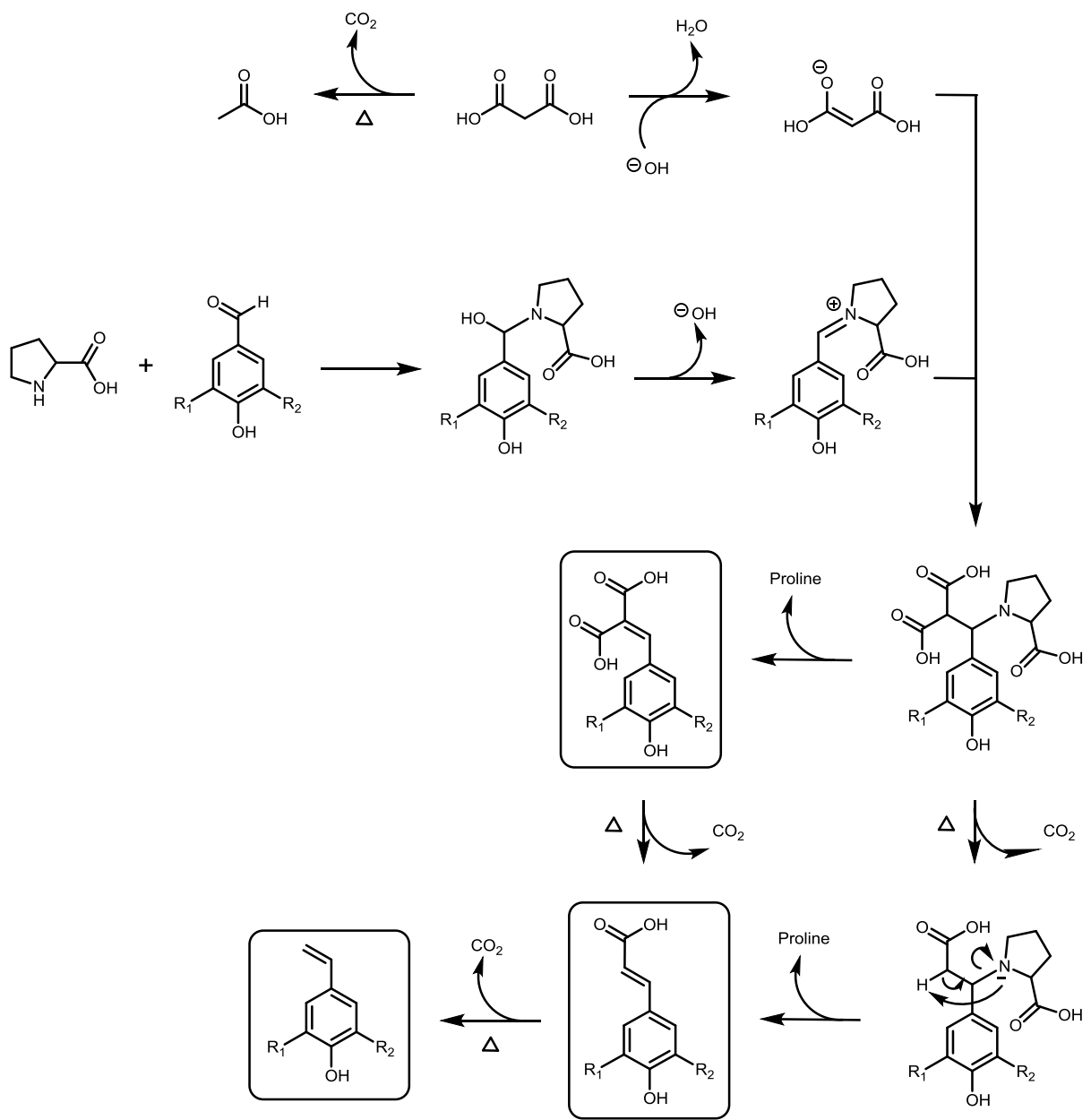

\section{Scheme 1 : Knoevenagel condensation of $p$-hydroxycinnamic aldehydes using malonic acid and proline as catalyst}

In their work dedicated to the preparation of $\alpha, \beta$-unsaturated ketones through aldol condensation, De Winter et al. found the following conditions: 1 equivalent of ketone, 1.2 equivalent of aldehyde, $10 \mathrm{wt} \% \mathrm{MgO}, 1$ equivalent of Lproline in methanol $(0.45 \mathrm{M})$ at $50{ }^{\circ} \mathrm{C}$. These conditions were thus directly applied to synthesize sinapic acid from malonic acid and syringaldehyde. After 4 hours of reaction, only $10 \%$ sinapic acid conversion for $27 \%$ di-acid and $63 \%$ syringaldehyde was measured by ${ }^{1} \mathrm{H}$ NMR. Consequently, it was concluded that, under such conditions, the reaction was possible but optimization was required in order to access satisfying yields and selectivity.

In order to have a better understanding of the reaction, the influence of various reaction parameters/variables (i.e., temperature, concentration, equivalent of malonic acid, equivalent of $\mathrm{MgO}$ and equivalent of proline) were investigated by performing a design of experiment (DoE) (Table 1). For a more sustainable process, methanol was substituted by ethanol. All sets of reaction conditions performed for the DoE and the corresponding results can be found in the Supporting Information.

\begin{tabular}{cccc} 
Variables & \multicolumn{3}{c}{ Levels } \\
\cline { 2 - 4 } & -1 & 0 & 1 \\
\hline Temperature $\left({ }^{\circ} \mathrm{C}\right)$ & 40 & 60 & 80 \\
Concentration $\left(\mathrm{mol} . \mathrm{L}^{-1}\right)$ & 0.1 & 0.3 & 0.5 \\
Malonic acid & 1 & 2 & 3 \\
equivalents & & & \\
MgO equivalents & 0.1 & 0.6 & 1.1 \\
Proline equivalents & 0.1 & 0.6 & 1.1 \\
\hline
\end{tabular}

Table 1: Variables and their variation corresponding to defined levels of the DoE. 
To find a relationship between theses variables and response surface, the following second-order polynomial equation was used:

$$
Y=\alpha_{0}+\sum_{i} \alpha_{i} x_{i}+\sum_{i} \alpha_{j} x_{i}^{2}+\sum_{i j} \alpha_{i j} x_{i} x_{j}
$$

where $Y$ represents the response (conversion), $x_{i}$ are the variables, $\alpha_{0}$ is a constant and $\alpha_{i}, \alpha_{j}$ and $\alpha_{i j}$ are the linear, quadratic and interaction coefficients. Regression coefficients were determined by multiple linear regressions (MLR). The significant parameters in the model were found by analysis of their p-value $(<0.05)$. The model validation was based on the variance (ANOVA) for each response, namely, by the analysis of $R^{2}$, $\mathrm{Q}^{2}$, and lack of fit (LOF) test. $\mathrm{R}^{2}$ measures how well the regression model fits the experimental data, $\mathrm{Q}^{2}$ shows an estimate of the future prediction precision, and LOF assesses whether the models error is comparable to the replicate error. A D-optimal design consisting in 31 experiments, including 3 three replications at the central point to evaluate their reproducibility, was used to determine the optimum set of experimental parameters to optimize the reaction conversion.

The experimental data of the D-Optimal design was fitted to the second-order polynomial equation (Eq. 1). Analysis of variance (ANOVA) shows a good correlation of the second-order polynomial model between the response (conversion) and the significant variables $(\mathrm{p}<0.05)$. The $\mathrm{p}$-value of the regression model below 0.05 shows the statistical significance of the polynomial regression. The lack of fit $(\mathrm{p}>0.05)$ shows the low replicate errors of the model. Finally, the design gives a very good coefficient of determination $\left(\mathrm{R}^{2}=0.952>0.5\right)$ and acceptable coefficient of cross-validation $\left(\mathrm{Q}^{2}=0.868>0.5\right)$ that corresponds to a good fit and prediction of the model. The scheme 1 shows the coefficients ( $\alpha_{0}$ as constant, $\alpha_{i}, \alpha_{j}$ and $\alpha_{i j}$ of the Eq. 1$)$ of the model for the response. A positive value means a positive influence on the conversion while a negative value means a negative influence.

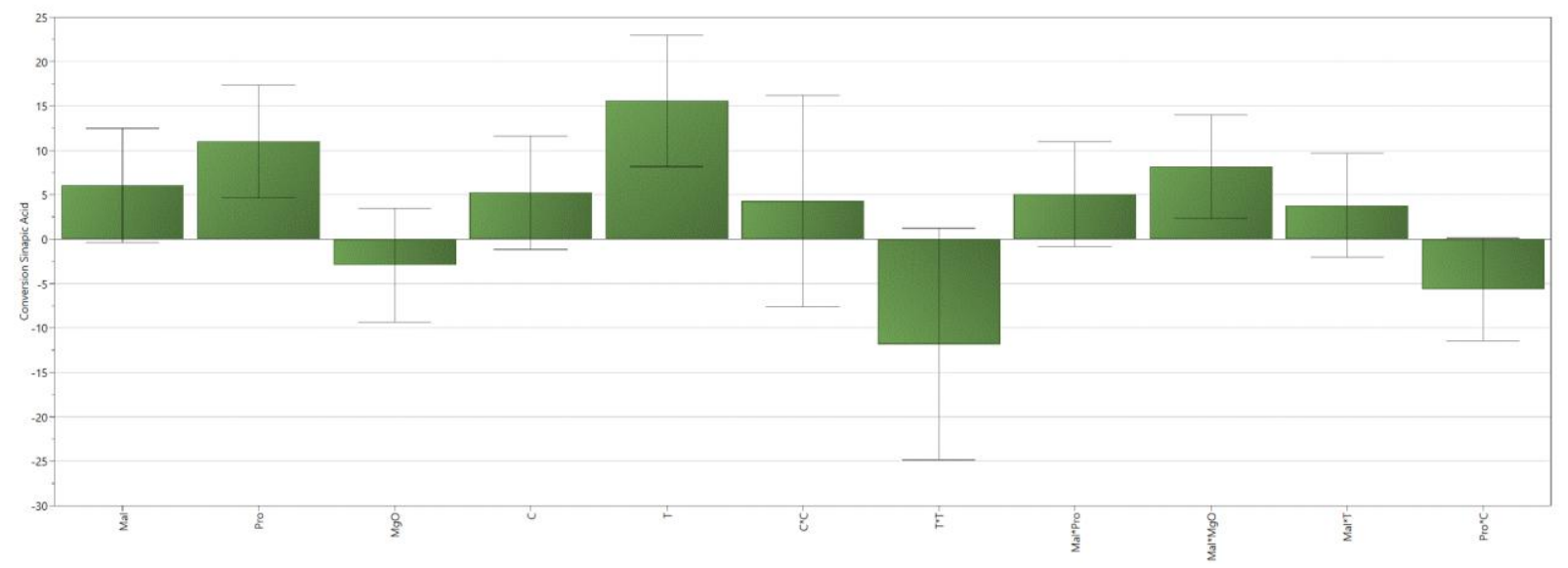

Scheme 2: Regression coefficients of quadratic model, Eq 1.

DoE results show that the temperature, concentration, equivalent of malonic acid and equivalent of proline have a positive impact on the conversion of syringaldehyde into sinapic acid whereas equivalent of $\mathrm{MgO}$ has a slightly negative one, with optimum values on the intervals of study according to their respective quadratic terms. Moreover, concentration interacts negatively with equivalents of proline, which suggests that the catalytic cycle is influenced by the concentration. The influence of the number of equivalent of $\mathrm{MgO}$, the concentration, the concentration quadratic terms and that of the equivalent of malonic acid towards the temperature are not significant on the conversion rate (p-value> 0.1). Finally, the equation of the model (Eq. 2) is as follows:

Conversion into Sinapic acid $(\%)=52.66+6.06 x \mathrm{xq}$. malonic $+11.01 \mathrm{xEq}$. proline $+15.59 \mathrm{xTemp}-$ $11.81 \times \mathrm{Temp}^{2}+5.06 \mathrm{x}($ Eq. malonic*Eq. proline $)+8.16 \mathrm{x}($ Eq. malonic acid*Eq. MgO) $-5.66 \mathrm{x}(\mathrm{Eq}$. proline*concentration) (Eq. 2) 


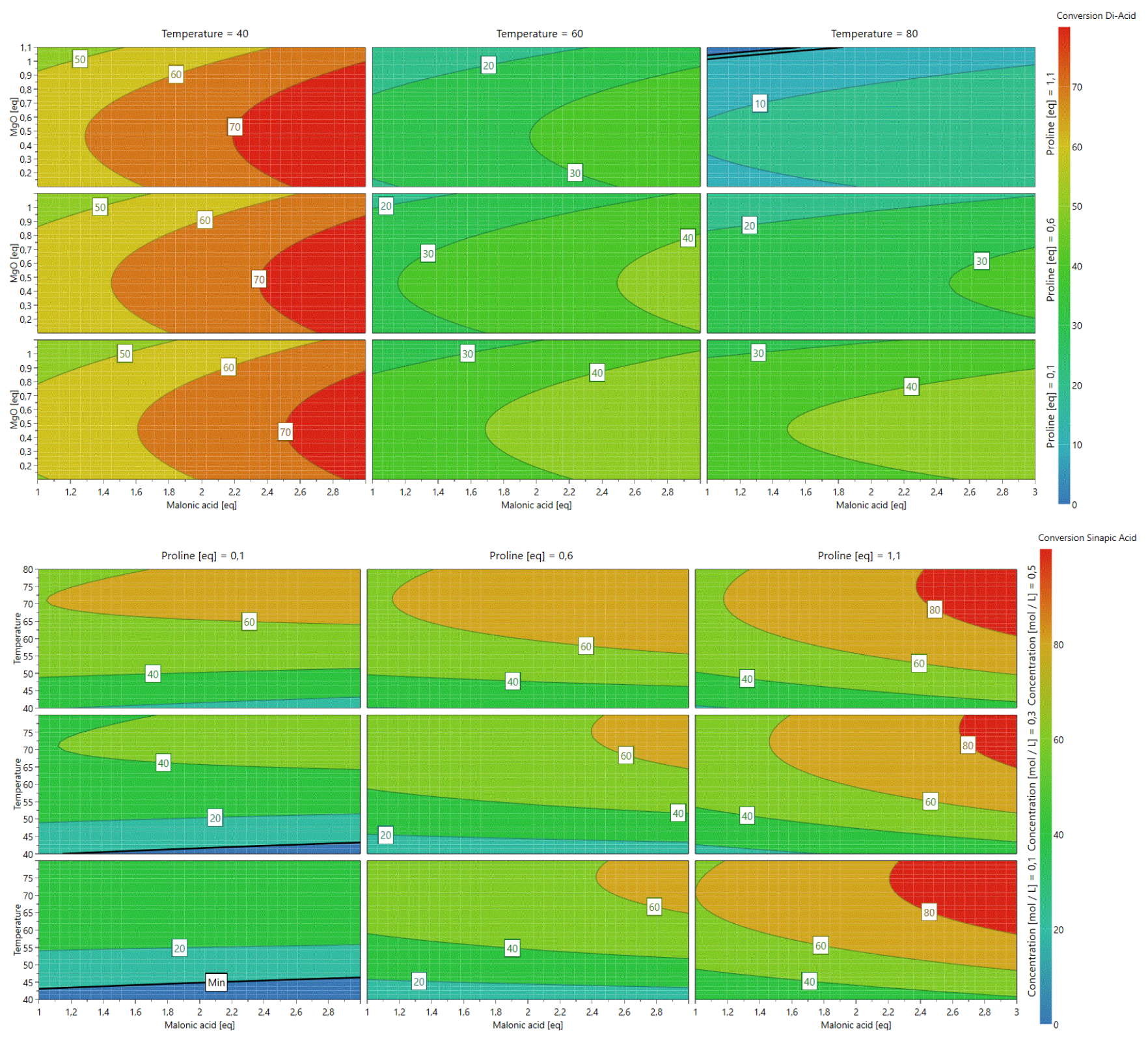

Scheme 3 : Contour plot of syringaldehyde conversion into sinapic acid

The analysis of the 4D response contour allowed the visualization of the influence of each parameter (Scheme 3 ). In the interval considered, the optimal temperature was evaluated at $80{ }^{\circ} \mathrm{C}$ and the optimal number of equivalent of malonic acid, proline and $\mathrm{MgO}$ at 2.8, 0.8 and 0.25 , respectively. Applying these conditions allowed a total consumption of syringaldehyde with a conversion into sinapic acid and sinapic di-acid of $60 \%$ and $38 \%$, respectively (Table 2 , entry 1 ).

The maximum sinapic acid conversion being relatively low despite the optimization, one or more reaction parameters remained to be adjusted using the classical OVAT approach. Magnesium oxide having an insignificant influence on the reaction, the reaction was first performed without $\mathrm{MgO}$ at relatively high concentration $(0.5 \mathrm{M})$. Doing so, the yield of sinapic acid increased up to $82 \%$, whereas that of sinapic di-acid decreased (18\%) (Table 2, entry 2). This result undoubtedly confirmed that magnesium oxide has no effect on our Knoevenagel reaction conditions, whereas the concentration seems to have a positive effect. These results correlate with the importance of the concentration suggested by the DoE.

From a sustainable point of view, the use of 2.8 equivalents of malonic acid seemed to be excessive for a reaction which could be theoretically equimolar. The reaction was thus performed using only 2 equivalents of malonic acid (Table 2, entry 3). Moreover, the parameter Equivalent of proline/concentration having negative 
effect on the formation of sinapic acid, the quantity of proline was reduced to 0.5 equivalent. Almost the same sinapic acid conversion (80\%) was obtained using these conditions compared to the previous ones (Table 2, entry 3). At this point of the optimization, a relatively significant quantity of sinapic di-acid (15\%) was still observed.

Looking deeper into the experimental results of the DOE, the influence of temperature on the decarboxylation of the sinapic di-acid into the sinapic acid has been confirmed. The reaction was then carried out at higher temperature $\left(90^{\circ} \mathrm{C}\right)$ to promote the decarboxylation and drive the equilibrium of the reaction towards sinapic acid. Doing so, the sinapic di-acid was completely consumed but the formation of the corresponding vinyl phenol was observed (10\%) (Table 2, entry 4). Indeed, increasing the temperature promotes the second decarboxylation (Scheme 1), it is therefore crucial to finely control the reaction temperature to favour sinapic acid production while limiting that of the di-acid and the vinyl phenol.

In a previous paper, we have illustrated the impact of the equivalent of catalyst (piperidine) on the vinyl phenol formation. ${ }^{9}$ They showed that a large amount of catalyst promoted its formation. Based on this observation, the equivalent of proline was modulated from 0.8 to 0.3 in order to conclude about the proline effect on the reaction (Table 2, entries 4-6). As previously observed, increasing the equivalent of catalyst (0.8) induced vinyl phenol formation (24\%) (Table 2, entry 5). A decrease to 0.3 equivalent promoted the formation of only $11 \%$ of the corresponding vinyl phenol but also limited the first decarboxylation step maintaining $11 \%$ of sinapic di-acid (Table 2, entry 6). 0.5 equivalent of proline appeared as the perfect compromise for the formation of sinapic acid while limiting that of sinapic di-acid and vinyl phenol.

In summary, through the combination of the DoE and OVAT, optimal conditions were found as 1 equivalent of syringaldehyde, 2 equivalents of malonic acid, 0.5 equivalent of proline at $90{ }^{\circ} \mathrm{C}$ during 16 hours in ethanol $(0.5 \mathrm{M})$ (Table 2, entry 4$)$. Obtaining exclusively sinapic acid being impossible, purification is inevitable. With regards to chromatographic purification, it is easier to remove vinyl phenol, more polar, than sinapic diacid. Moreover, vinyl phenol being an oily compound, it could be also eliminated during the simple sinapic acid precipitation procedure followed by a filtration. These conditions were then applied to the other $p$ hydroxycinnamic acids.

\begin{tabular}{|c|c|c|c|c|c|c|c|c|}
\hline & $\begin{array}{c}\text { Malonic } \\
\text { Acid } \\
(\text { Equiv) }\end{array}$ & $\begin{array}{c}\text { Proline } \\
(\text { Equiv) }\end{array}$ & $\begin{array}{c}\text { MgO } \\
(\text { Equiv) }\end{array}$ & $\begin{array}{c}\text { Temperature } \\
\left({ }^{\circ} \mathbf{C}\right)\end{array}$ & $\begin{array}{c}\text { Concentration } \\
(\mathbf{M})\end{array}$ & $\begin{array}{c}\text { Conversion } \\
\text { Di-acid } \\
(\boldsymbol{\%})\end{array}$ & $\begin{array}{c}\text { Conversion } \\
\text { Sinapic Acid } \\
(\boldsymbol{\%})\end{array}$ & $\begin{array}{c}\text { Conversion } \\
\text { V. Phenol } \\
(\boldsymbol{\%})\end{array}$ \\
\hline 1 & 2.8 & 0.8 & 0.25 & 80 & 0.1 & 38 & 60 & 0 \\
\hline 2 & 2.8 & 0.8 & 0 & 80 & 0.5 & 18 & 82 & 0 \\
\hline 3 & 2 & 0.5 & 0 & 80 & 0.5 & 14 & 80 & 0 \\
\hline 4 & 2 & 0.5 & 0 & 90 & 0.5 & 0 & 90 & 10 \\
\hline 5 & 2 & 0.8 & 0 & 90 & 0.5 & 0 & 76 & 24 \\
\hline 6 & 2 & 0.3 & 0 & 90 & 0.5 & 11 & 78 & 11 \\
\hline
\end{tabular}

Table 2 : Optimization of the Knoevenagel condensation on syringaldehyde in ethanol

Applying theses conditions to the other $p$-hydroxybenzaldehydes provided the corresponding $p$-hydroxycinnamic acids good yields while limiting the presence of di-acid and vinyl phenol (Table 3, entries 2-4). The syntheses were carried out on gram scales. Nevertheless, the previous optimization having been performed on the more activated aldehyde (i.e., syringaldehyde), optimization of the reaction conditions should be carried out for every single $p$ hydroxybenzaldehydes to access higher yields.

\begin{tabular}{|c|c|c|c|}
\hline Substrates & Phenolic acids & $\begin{array}{c}\text { Conversion } \\
\mathbf{\%}\end{array}$ & $\begin{array}{c}\text { Yield }^{\mathbf{b}} \\
\mathbf{\%}\end{array}$ \\
\hline 4-Hydroxybenzaldehyde & $p$-Coumaric acid & 55 & 50 \\
\hline 3,4-Dihydroxybenzaldehyde & Caffeic acid & 71 & 68 \\
\hline Vanillin & Ferulic acid & 72 & 69 \\
\hline Syringaldehyde & Sinapic acid & 87 & 85 \\
\hline
\end{tabular}


Table 3 : Conversion rate and yields of natural occuring $p$-hydroxycinnamic acids

$\left({ }^{a}\right.$ conversion were determined by ${ }^{l} H$ NMR of the crude reaction mixture; ${ }^{b}$ yields were calculated from isolated product after purification)

\section{CONCLUSION}

An efficient and sustainable proline-mediated Knoevenagel condensation of malonic acid and syringaldehyde in ethanol has been developed in order to access principally to sinapic acid. We successfully substituted the classical petro-sourced and toxic catalysts, such as pyridine/piperidine, by proline and toxic solvent by ethanol to provide a greener procedure. Through a combination of DoE and OVAT each parameters have been optimized to favor sinapic acid production ( $87 \%{ }^{1} \mathrm{H}-\mathrm{NMR}$ conversion, $85 \%$ isolated yield) over that of the two other side-products (di-acid and vinly phenol). This set of optimized conditions was applied to other $p$-hydroxybenzaldehydes, prodiving the corresponding $p$-hydroxycinnamic acids in good yields (55-72\% ${ }^{1} \mathrm{H}$-NMR conversion, $50-69 \%$ isolated yield). This sustainable route offers an interesting approach to access quickly and efficiently naturally occurring $p$ hydroxycinnamic acids while limiting the toxicity risks associated with their production. Further optimisations such as the use of supported proline to recycle the catalyst, or the combination of proline and micro-wave activation to reduce the reaction time will be investigated and reported in due time.

\section{ASSOCIATED CONTENT}

\section{Supporting Information.}

The Supporting Information is available free of charge on the ACS Publications website at DOI:

Experimental details and NMR spectra are available

\section{Corresponding Author}

E-mail: florent.allais@ agroparistech.fr (Florent Allais)

\section{Notes}

The authors declare no competing financial interest.

\section{ACKNOWLEDGMENT}

The authors are grateful to Agence Nationale de la Recherche (ANR, ANR-17-CE07-0046), Région Grand Est, Conseil Départemental de la Marne and Grand Reims for financial support.

\section{ABBREVIATIONS}

DoE, Design of Experiment; OVAT, One Variobale At a Time

\section{REFERENCES}

1. List, B., Emil Knoevenagel and the Roots of Aminocatalysis. Angew. Chem., Int. Ed. 2010, 49 (10), 1730-1734.

2. (a) Jaufurally, A. S.; Teixeira, A. R. S.; Hollande, L.; Allais, F.; Ducrot, P.-H., Optimization of the laccase-catalyzed synthesis of $( \pm)$-syringaresinol and study of its thermal and antiradical activities. ChemistrySelect 2016, 1 (16), 5165-5171; (b) Janvier, M.; Hollande, L.; Jaufurally, A. S.; Pernes, M.; Menard, R.; Grimaldi, M.; Beaugrand, J.; Balaguer, P.; Ducrot, P. H.; Allais, F., Syringaresinol: A Renewable and Safer Alternative to Bisphenol A for Epoxy-Amine Resins. ChemSusChem 2017, 10 (4), 738-746. 
3. (a) Reano, A. F.; Pion, F.; Domenek, S.; Ducrot, P. H.; Allais, F., Chemo-enzymatic preparation and characterization of renewable oligomers with bisguaiacol moieties: promising sustainable antiradical/antioxidant additives. Green Chem. 2016, 18 (11), 3334-3345; (b) Reano, A.; Domenek, S.; Pernes, M.; Beaugrand, J.; Allais, F., Ferulic Acid-based Bis/trisphenols as Renewable Antioxidants for polypropylene and poly(butylen succinate). ACS sustainable Chem. Eng. 2016, 4 (12), 6562-6571; (c) Reano, A.; Cherubin, J.; Peru, A. M.; Wang, Q.; Clement, T.; Domenek, S.; Allais, F., Structure-activity Remationships and Structural design Optimization of a Series of $p$-hydroxycinnamic Acids-basedbisand trisphenols as novel sustainable Antiradical/antioxidant additives. ACS sustainable Chem. Eng. 2015, 3, 3486-3496.

4. (a) Allais, F.; Martinet, S.; Ducrot, P. H., Straightforward total synthesis of 2-O-feruloyl-Lmalate, 2-O-sinapoyl-L-malate and 2-O-5-hydroxyferuloyl-L-malate. Synthesis 2009, 21, 3571-3578; (b) Baker, L. A.; Staniforth, M.; Flourat, A. L.; Allais, F.; Stavros, V. G., Gas-Solution Phase Transient Absorption Study of the Plant Sunscreen Derivative Methyl Sinapate. ChemPhotoChem 2018, 2 (8), 743-748.

5. (a) Hollande, L.; Jaufurally, A. S.; Ducrot, P. H.; Allais, F., ADMET Polymerization of Biobased Monomers Deriving from Syringaresinol. RSC Adv. 2016, 6, 44297; (b) Barbara, I.; Flourat, A. L.; Allais, F., Renewable Polymers Derived from Ferulic Acid and Biobased Diols via ADMET. Eur. Polym. J. 2015, 62, 236; (c) Pion, F.; Oulame, M. Z.; Ducrot, P. H.; Allais, F., Renewable Alternating Aliphatic-aromatic Polyurethanes Derived from Bio-based Ferulic Acid, Diols and Isocyanates: Sustanaible Polymers with Tunable Thermal Properties. Eur. Polym. J. 2015, 63, 186; (d) Menard, R.; Caillol, S.; Allais, F., Chemo-enzymatic Synthesis and Characterization of Renewable Thermoplastic and Thermoset Isocyanate-free poly(hydroxy)urethanes from Ferulic Acid Derivatives. ACS sustainable Chem. Eng. 2017, 5, 1446-1456; (e) Kasmi, S.; Gallos, A.; Beaugrand, J.; Paes, G.; Allais, F., Ferulic acid derivatives used as biobased powders for a convenient plasticization of polylactic acid in continuous hot-melt process. Eur. Polym. J. 2019, 110, 293-300.

6. Knoevenagel, E., Ueber eine Darstellungsweise der Glutarsaure. Beriche der deutschen chemischen Gesellschaft 1894, 27, 2345-2346.

7. Forbes, D. C.; Law, A. M.; Morrison, D. W., The Knoevenagel reaction: analysis and recycling of the ionic liquid medium. Tetrahedron Lett. 2006, 47 (11), 1699-1703.

8. (a) Hangarge, R. V.; Jarikote, D. V.; Shingare, M. S., Knoevenagel condensation reactions in an ionic liquid. Green Chem. 2002, 4 (3), 266-268; (b) Ouyang, F.; Zhou, Y.; Li, Z.-M.; Hu, N.; Tao, D.-J., Tetrabutylphosphonium amino acid ionic liquids as efficient catalysts for solvent-free Knoevenagel condensation reactions. Korean J. Chem. Eng. 2014, 31 (8), 1377-1383; (c) Hu, X.; Ngwa, C.; Zheng, Q., A Simple and Efficient Procedure for Knoevenagel Reaction Promoted by Imidazolium-Based Ionic Liquids. Curr. Org. Synth. 2016, 13 (1), 101-110; (d) Zhao, S.; Wang, X.; Zhang, L., Rapid and efficient Knoevenagel condensation catalyzed by a novel protic ionic liquid under ultrasonic irradiation. $R S C$ Adv. 2013, 3 (29), 11691-11696.

9. Mouterde, L. M. M.; Allais, F., Microwave-Assisted Knoevenagel-Doebner Reaction: An Efficient Method for Naturally Occurring Phenolic Acids Synthesis. Front Chem 2018, 6, 426.

10. Pasha, M. A.; Manjula, K., Lithium hydroxide: a simple and an efficient catalyst for Knoevenagel condensation under solvent-free Grindstone method. J. Saudi Chem. Soc. 2011, 15 (3), 283-286.

11. (a) Leelavathi, P.; Kumar, S. R., Niobium(V) chloride-catalyzed Knoevenagel condensation. An efficient protocol for the preparation of electrophilic alkenes. J. Mol. Catal. A: Chem. 2005, 240 (1-2), 99-102; (b) Ogiwara, Y.; Takahashi, K.; Kitazawa, T.; Sakai, N., Indium(III)-Catalyzed Knoevenagel Condensation of Aldehydes and Activated Methylenes Using Acetic Anhydride as a Promoter. J. Org. Chem. 2015, 80 (6), 3101-3110; (c) Zhang, H.; Han, M.; Chen, T.; Xu, L.; Yu, L., Poly(Nisopropylacrylamide-co-L-proline)-catalyzed Claisen-Schmidt and Knoevenagel condensations: unexpected enhanced catalytic activity of the polymer catalyst. $R S C A d v \cdot \mathbf{2 0 1 7}, 7$ (76), 48214-48221; (d) He, Y.-H.; Hu, Y.; Guan, Z., Natural $\alpha$-amino acid L-lysine-catalyzed Knoevenagel condensations of $\alpha, \beta$-unsaturated aldehydes and 1,3-dicarbonyl compounds. Synth. Commun. 2011, 41 (11), 1617-1628; 
(e) Rahmati, A.; Vakili, K., L-Histidine and L-arginine promote Knoevenagel reaction in water. Amino Acids 2010, 39 (3), 911-916.

12. (a) Wang, Y.; Shang, Z.-c.; Wu, T.-X.; Fan, J.-c.; Chen, X., Synthetic and theoretical study on proline-catalyzed Knoevenagel condensation in ionic liquid. J. Mol. Catal. A: Chem. 2006, 253 (1-2), 212-221; (b) Liu, X.-h.; Fan, J.-c.; Liu, Y.; Shang, Z.-c., L-Proline as an efficient and reusable promoter for the synthesis of coumarins in ionic liquid. J. Zhejiang Univ., Sci., B 2008, 9 (12), 990-995; (c) Venkatanarayana, M.; Dubey, P. K., L-Proline-catalyzed Knoevenagel condensation. A tandem synthesis of 3-acetylcoumarinoindoles and their N-alkyl derivatives by using PEG-600 as the reaction medium. $J$. Heterocycl. Chem. 2014, 51 (4), 877-882.

13. de Winter, T. M.; Balland, Y.; Neski, A. E.; Petitjean, L.; Erythropel, H. C.; Moreau, M.; Hitce, J.; Coish, P.; Zimmerman, J. B.; Anastas, P. T., Exploration of a Novel, Enamine-Solid-Base Catalyzed Aldol Condensation with C-Glycosidic Pyranoses and Furanoses. ACS Sustainable Chem. Eng. 2018, 6 (9), 11196-11199.

14. Bermudez, E.; Venture, O. N.; Senz Méndez, P., Mechanism of the Organocatalyzed Decarboxylative Knoevenagel-Doebner Reaction. A Theoretical Study. J. Phys. Chem. A. 2010, 114, 13086-13092.

15. Caires, F. J.; Lima, L. S.; Carvalho, C. T.; Giagio, R. J.; Ionashiro, M., Thermal behaviour of malonic acid, sodium malonate and its compounds with some bivalent transition metal ions.

Thermochim. Acta 2010, 497 (1-2), 35-40.

16. (a) Aldabalde, V.; Risso, M.; Derrudi, M. L.; Geymonat, F.; Seoane, G.; Gamenara, D.; SaenzMendez, P., Organocatalyzed decarboxylation of naturally occurring cinnamic acids: potential role in flavoring chemicals production. Open J. Phys. Chem. 2011, 1 (3), 85-93; (b) Sinha, A. K.; Sharma, A.; Joshi, B. P., One-Pot Two-Step Synthesis of 4-Vinylphenols from 4-Hydroxy Substtitued Benzaldehydes under Microwave Irradiatio: a New Perspective on the Classical Knoevenagel-Doebner Reaction.

Tetrahedron 2007, 63, 960-965. 